\title{
INCLUSÃO DIGITAL NAS ESCOLAS: um estudo de caso em uma turma do Ensino Fundamental de uma escola municipal no Noroeste de Minas Gerais
}

\section{DIGITAL INCLUSION IN SCHOOLS: a case study in a group of Fundamental Education of a municipal school in Northeast of Minas Gerais}

\section{José Ivan Lopes ${ }^{1}$ \\ Caiene Avani dos Reis Caixêta Salgado ${ }^{2}$ \\ Poliana Patrícia Fortunato ${ }^{3}$ https://doi.org/10.29327/216986.1.1-2}

RESUMO: O presente artigo tem como objetivo averiguar a importância e a necessidade de conhecer os aspectos pedagógicos de uma escola e a forma como ocorre a inclusão digital, destacando a positividade para a melhoria do ensino-aprendizagem dos seus respectivos alunos. A pesquisa foi realizada na Escola Municipal Doutor Sérgio Ulhoa, na cidade de Guarda-Mór, foi escolhida a turma do $3^{\circ}$ ano do Ensino Fundamental I. A pesquisa utilizada foi qualitativa e quantitativa, através de questionários aplicados aos alunos, à professora Solange Dayrele e à diretora Tallita. Assim, foi possível averiguar a existência de laboratório de informática e se os equipamentos de informática são utilizados, além de analisar a eficiência do processo ensino-aprendizagem a partir da utilização dos referidos equipamentos.

Palavras-chave: Inclusão digital; Processo ensinoaprendizagem; Pesquisa.

ABSTRACT: This article aims to ascertain the importance and the need to know the pedagogical aspects of a school and the way digital inclusion occurs, highlighting the positivity for improving the teaching-learning of its respective students. The research was carried

\footnotetext{
${ }^{1}$ Mestre em Ciências da Religião pela PUC Minas. Especialista em Pedagogia Empresarial pela Faculdade do Noroeste de Minas (FINOM). Licenciado em Filosofia pela PUC Minas e em Teologia pelo Instituto de Teologia São José - Mariana-MG. Diretor Acadêmico da Faculdade FINOM. http://lattes.cnpq.br/3827559211025109 E-mail: diretoria@ finom.edu.br

${ }^{2}$ Licenciada em Pedagogia EaD pela Faculdade do Noroeste de Minas (FINOM). E-mail: caienecaixeta@yahoo.com.br

${ }^{3}$ Licenciada em Pedagogia EaD pela Faculdade do Noroeste de Minas (FINOM). E-mail: polianapatriciaokoro@hotmail.com
}

Educação In Loco, v.01, n. 01, jan.-jun. 2020 - ISSN 2675-4304 
out at the Municipal School Doctor Sérgio Ulhoa, in the city of Guarda-Mór, the 3rd year class of Elementary School I was chosen. The research used was qualitative and quantitative, through questionnaires applied to students, to teacher Solange Dayrele and to the Tallita director. Thus, it was possible to ascertain the existence of a computer lab and whether computer equipment is used, in addition to analyzing the efficiency of the teaching-learning process from the use of such equipment.

Keywords: Digital inclusion; Teaching-learning process; Pesearch.

\section{Introdução}

O presente artigo tem como objetivo averiguar a importância e a necessidade de conhecer os aspectos pedagógicos de uma escola e a forma como ocorre a inclusão digital, destacando a positividade para a melhoria do ensino-aprendizagem dos seus respectivos alunos.

$\mathrm{O}$ aprimoramento na qualidade na qualidade do ensino por meio de trabalhos escolares bem elaborados passa obrigatoriamente pela utilização das tecnologias de informação, que devem ser inseridas no currículo escolar dos estudantes. No mundo tecnológico em que vivemos não é possível fugir dos avanços que nos rodeiam e nos norteiam. Tais avanços possibilitam ainda uma didática casa vez mais diversificada e atraente.

Antes mesmo do seu ingresso no ambiente escolar, a criança já está marcada por um ambiente rodeado de tecnologias, pois em casa ela já utiliza aparelhos como: notebooks, tablets, celulares, entre outros. Muitas crianças têm facilidade ao manusear tais aparelhos. Existem, por outro lado, muitos educadores e profissionais da área da educação que não possuem o mesmo traquejo, seja por falta de uma formação, ou por falta de incentivos para se adequarem ao uso e às novas tecnologias.

A gestão escolar, por sua vez, tem o compromisso de incentivar os docentes para a capacitação e para darem suas opiniões acerca da metodologia a ser adotada na formação dos alunos, para inovar o ensino-aprendizagem, por meio da utilização das tecnologias disponíveis, pois através de trabalhos e pesquisas com a utilização de 
tais meios torna possível alcançar sucesso e atingir os objetivos educacionais.

Através de várias análises e estudos, buscando analisar a questão da utilização das tecnologias na educação, aplicou-se um questionário à equipe da escola Doutor Sérgio Ulhoa. Os colaboradores que participaram da pesquisa por meio da resposta ao questionário: a gestora, os alunos e a professora da turma do $3^{\circ}$ ano do Ensino Fundamental I. O questionário buscou conhecer mais sobre a realidade de cada um dos membros da turma, conhecendo suas habilidades com as tecnologias dos computadores, celulares e aplicativos de joguinhos on-line, os DVDs, data show. Os resultados alcançados foram identificados no decorrer do trabalho e apresentados por meio de gráficos.

\section{Referencial Teórico}

Ao se falar sobre inclusão digital nas escolas não estamos nos referindo somente do que se refere à instalação de equipamentos de informática. Sabe-se, porém, que o computador e todas as demais tecnologias vieram para quebrar barreiras, pois essa ferramenta contribui para que seja possível atingir um ensino-aprendizagem de excelência.

De acordo com Bonis (2000), as tecnologias de informação jamais substituirão o educador em sala de aula, ele é mediador do conhecimento e de suma importância no processo de ensino, e com a inclusão digital, fica ainda mais satisfatório ainda, pois somando tecnologia e o professor pra auxiliar na busca por um aprendizado mais atrativo, o saber vai ser muito mais promissor, dando expansividade ao pensamento, e um novo mar de conhecimentos e despertando curiosidades dos alunos.

Os equipamentos de informática já estão inseridos nos laboratórios de muitas escolas estaduais e municipais, mas é possível averiguar na prática educacional que sua utilização é pouco frequente. Sendo assim, pode-se afirmar que a utilização da tecnologia da informática é apenas uma atividade isolada incluída, de forma aleatória, na rotina dos alunos, pois não faz parte de um projeto 
pedagógico amplo e consistente. Na maior parte do tempo, ao longo do dia, os laboratórios encontram-se fechados, principalmente nos horários de aula, fazendo entender que uma ferramenta extremamente eficiente no processo do ensino aprendizado é, por outro lado, pouco utilizada.

As novas tecnologias de informação, se bem manuseadas e aproveitadas pelos educadores, que, por sua vez, devem ser instruídos e especializados na área da informática, proporcionam mudanças e inúmeras possibilidades de inovações tecnológicas. Nesse sentido, irão abrir um leque de novas oportunidades positivas, podendo se dizer que serão alcançados maiores resultados. No que se refere às aulas, elas serão mais atrativas e envolventes para seus respectivos alunos.

Pelas razões elencadas acima, os professores precisam adquirir habilidades técnicas e pedagógicas, respondendo aos grandes desafios que envolvem a área das novas tecnologias na educação. Pois, segundo Valente (1996), além do domínio do conhecimento acerca da informática, os professores devem ainda conhecer outras tecnologias, tais como: celular, data-show e demais equipamentos tecnológicos e eletrônicos.

A inclusão digital não pode e não deve ser inserida nas escolas e na vida acadêmica dos alunos sem que os professores tenham ao menos um conhecimento prévio das máquinas e dos equipamentos digitais. Eles devem ser preparados para atuar pedagogicamente, pois do contrário o projeto pedagógico de inclusão da tecnologia na educação será fadado ao fracasso e os objetivos não serão alcançados. A internet, por sua vez é um excelente recurso no processo ensinoaprendizagem e, por essa razão precisa fazer parte do processo pedagógico para ensino básico nas escolas.

Segundo Santos (2009), a popularização da informática e ao acesso à rede mundial de computadores ocorreu por volta de 1990 e, a partir de então, a sonhada era digital passou a fazer parte do dia a dia de um grande número de pessoas em todo o Brasil e no mundo. Com a introdução da tecnologia e da internet, a percepção das pessoas começou a mudar. Nesse sentido, surgiram vários pontos de vista acerca da utilização da tecnologia na educação, por um lado existem aqueles que querem inovar a prática pedagógica e inserir os 
computadores nas salas de aula, e, por outro lado, um grupo de profissionais opta pela educação por meio de livros, papéis, fotocópias.

A especialização na área da informática para os professores está cada vez mais promissora, pois os currículos serão minuciosamente inovados, abolindo o tradicionalismo de algumas práticas educativas e partindo para as práticas inovadoras virtuais, aprimorando a teoria e a prática educacional.

É preciso que haja mais ambientes que propiciem a importância de educar navegando de lidar com os novos conflitos por meio das máquinas. É necessário experimentar essa realidade e refletir sobre ela sempre buscando caminhos de crescimento.

Dessa forma, educar para a era da informação não significa apenas preparar o indivíduo para a apropriação da tecnologia e sua aplicação para melhorar o ensino. Sob nosso ponto de vista, educar para a era da informação extrapola a questão didática, das metodologias de ensino-aprendizagem, das didáticas usadas em sala de aula, necessitam de novos caminhos que levem em consideração a questão da autonomia na construção do conhecimento, o acesso à informação, à liberdade de expressar ideias, o respeito à diversidade e à multiculturalidade traduzido pela compreensão ao modo de pensar e viver de cada um. É uma educação que deverá estar centrada no aluno enquanto sujeito principal, na troca de saberes que ocorrem entre esses alunos ou sujeitos que estão em transformação a partir da compreensão dos diferentes pontos de vista sobre as tecnologias e suas funções no aprender e nos costumes individuais, ou até mesmo nas dificuldades existentes entre as pessoas, e entre as pessoas e as tecnologias intelectuais. (Moraes, 1997, p. 23).

De acordo com o ponto de vista da referida autora, a polêmica sobre as novas tecnologias na escola e deve ser superada, pois temos diante de nós um recurso atual que mudou e continuará mudando a vida das pessoas, assim como as formas de comunicação e até mesmo o relacionamento interpessoal.

Mesmo com a inserção das novas tecnologias, as escolas públicas, sejam elas estaduais ou municipais estão mais dissociadas do mundo, estão carentes de ferramentas para trabalhar com seus alunos 
e capacitar seus docentes. É preciso inovar sempre para atender a demanda de uma nova era, fortemente marcada pela informação. Assim a escola prepara seus alunos para se tornarem cidadãos comprometidos com o que fazem, cidadãos com valores éticos, com dignidade e honra. Formar cidadãos independentes, capazes de compor uma sociedade em que todos tenham seus direitos preservados.

Para Silveira (2011), ainda falta um longo caminho para avançar em termo de inclusão digital nas escolas. Para ele, o principal desafio a ser vencido para promover a inclusão digital no ambiente escolar é a insegurança dos professores quanto ao uso das novas tecnologias, uma vez que são desconfiados se essa nova forma de ensinar com o uso do computador será positiva na didática em sala e no processo ensino-aprendizagem.

Mais que das novas tecnologias, as mudanças na educação dependem de educadores, gestores e alunos maduros, intelectual, emocional e eticamente; pessoas curiosas, entusiasmadas, abertas, que saibam motivar e dialogar; pessoas com as quais valham à pena entrar em contato, porque dele saímos enriquecidos. (Silveira, 2011, p.18).

A humanidade está cada vez mais inserida tecnologicamente na era da informação, mas podem se considerar que ainda é muito baixo o número de pessoas que estão habilitadas e que possuem habilidades para manusear uma máquina, por mais simples que possa parecer pra muitos. É um requisito forte que atualmente a sociedade embarque cada vez mais na era da informação, pois os mercados de trabalho estão mais exigente, todos os dias se vê mais e mais qualificações para certa vaga de emprego, não só o diploma é fundamental, vai além disso, quanto mais cursos e qualificações se possui, mais chances terá, nos levando a entender definitivamente que aprender e buscar melhorias nunca é demais, principalmente na área da educação, informação, informática.

O objetivo da inclusão digital na sociedade, principalmente nas escolas, nada mais é que um grande passo que entidades sociais e governamentais dão para que a população e alunos das escolas tenham acesso e conhecimento necessário para mudar o futuro. É também 
importante todas as escolas lutarem para ter implantados em seus prédios os laboratórios de informática e também fazerem uso de tais.

Atualmente existem no mundo mais de 20 milhões de pessoas que não sabem ler e nem escrever, existem, por outro lado, pessoas que não tem acesso a internet. Tal constatação pode parecer absurda ou impossível quando se pensa que essas pessoas não são analfabetos digitais, mas é uma realidade.

A inclusão digital demanda três instrumentos básicos que devem ser disponibilizadas na escola, a saber: primeiro, a máquina para a conexão; em segundo lugar, o acesso a rede de internet que atenda a demanda de uma ou mais turma que acessam a rede concomitantemente; e, por fim, o pleno domínio destas máquinas, pois de nada adianta os professores ou a equipe possuir as ferramentas se não souber utilizá-las.

Geremias (2011) diz que a alfabetização digital dos professores e de toda a equipe escolar para que utilizem as tecnologias a favor da educação não ocorre de fato em pequenos cursos de pequena duração, a formação deve contemplar a teoria e a prática, que capacitem para a integração das tecnologias de informação com as práticas do cotidiano.

Com a implantação dos computadores nas escolas, os alunos se sentiram mais motivados e o lugar de estudos passou a ser mais atrativo. A busca pelo conhecimento somado ao fascínio pela máquina cria um ambiente propício para que interajam mais uns com os outros.

Segundo Piaget (2007), quatro são os estágios do desenvolvimento humano desde o nascimento até a fase adulta. No primeiro estágio sensório-motor, que consiste do nascimento até os dois anos de idade, a criança percebe o mundo através do movimento e da sensibilidade. No segundo estágio, o pré-operacional, a criança imita alguém ou algum objeto, sem ter modelos (pensamento simbólico) para então brincar mostrando uma situação imaginada. Já o terceiro estágio, as fases das operações concretas, que consiste dos sete aos doze anos é caracterizado pelo pensamento lógico e pelo raciocínio, tendo grande importância a manipulação de materiais concretos e o uso da imaginação. O período dos doze aos quinze anos é denominado por Piaget de fases das operações formais, uma vez que o indivíduo já consegue pensar hipotética e dedutivamente. 
Enquanto os alunos cursam as séries iniciais do ensino fundamental, eles estão na fase das operações concretas, e é nessa fase que os recursos tecnológicos são de suma importância, pois eles assimilam melhor os conteúdos que lhes são apresentados, por serem concretos, por serem prazerosos, por terem som, imagens, cores, movimentos, figuras e, dessa forma, eles se sentem desafiados por ser uma atividade diferente.

Somente o fato de sair do ambiente da sala de aula e se deslocar para o laboratório já motiva os alunos e o professor deve aproveitar a curiosidade em prol deles mesmos. Daí a importância da escola ter uma proposta pedagógica que contemple aulas de informática, por meio das quais os professores sejam capacitados, tanto na perspectiva pedagógica quanto na parte técnica visando capacitar os professores que porventura ainda não tenham o conhecimento necessário em relação à informática.

Portanto, tais professores devem ser preparados por meio de treinamentos, minicursos e palestras para que se adaptem a essa nova ferramenta de trabalho e se familiarizem com a tecnologia.

Assim, o professor diante dessas tecnologias passa a ser um facilitador, um colaborador do ensino, com pensamentos e com acesso a conhecimentos diversos e sem restrições para o ensino de seus alunos. A nova prática pedagógica estabelece uma nova visão de mundo e do ensino. Um professor atualizado se destaca por adquirir a visão de futuro, além de não perder as oportunidades e as possibilidades que o momento atual lhe proporciona. O professor que se destaca é aquele que ousa, e não aquele que teme que a máquina vá tomar o seu lugar na educação.

\section{Objetivos}

O presente artigo tem como objetivo averiguar a importância e a necessidade de conhecer os aspectos pedagógicos de uma escola e a forma como ocorre a inclusão digital, destacando a positividade para a melhoria do ensino-aprendizagem dos seus respectivos alunos.

\section{Metodologia}

Educação In Loco, v.01, n. 01, jan.-jun. 2020 
A metodologia usada para realização desse trabalho baseia-se em pesquisa aplicada em campo, a saber, na Escola Municipal Doutor Sérgio Ulhoa, na cidade de Guarda-Mór Minas Gerais, para se obter informações necessárias para a confirmação da hipótese. A entrevista foi realizada individualmente com alunos, professores, diretora da referida escola.

A pesquisa foi qualitativa e quantitativa, visando a melhor abordagem do problema, por meio de gráfico para apresentar de forma clara os resultados obtidos. Assim foi verificada a presença e a eficiência da utilização uso dos equipamentos de informática na escola.

O trabalho visou pesquisar quantos alunos tem acesso aos computadores, seja em casa ou na escola, e qual a freqüência da utilização do laboratório de informática na escola.

O tempo para a realização da pesquisa foi de uma semana. A aplicação e a compilação das respostas dados ao questionários possibilitou a obtenção de resultados.

\section{Resultados e Reflexões}

A pesquisa de campo, realizada na Escola Municipal Doutor Sérgio Ulhoa, na cidade de Guarda-Mór - Minas Gerais, entre os dias 11 a 14 de outubro de 2019 consistiu na aplicação de questionários aos alunos dos $3^{\circ}$ anos do Ensino Fundamental I. A turma é composta por 25 alunos, sendo que 24 alunos responderam ao questionário. Outro questionário foi aplicado à professora da turma e um à diretora da Escola.

Seguem os resultados do questionário aplicado aos alunos:

A primeira pergunta teve como objetivo averiguar os aparelhos a que os alunos têm acesso em casa. 


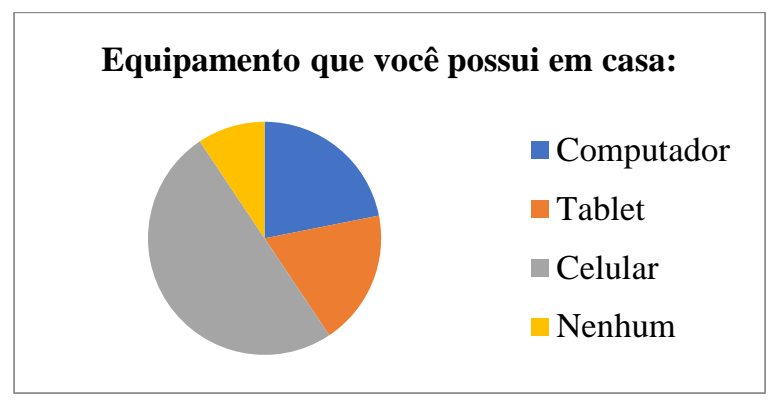

Gráfico 1: Elaborado pelos autores (2019)

As respostas dos alunos, representadas por meio do gráfico acima revelam que a minoria dos alunos não possui nenhum tipo de aparelho digital em casa. A maioria possui celular e um número razoável possui de computador e tablet.

A segunda pergunta procurou identificar a frequência que os alunos utilizam tais aparelhos:

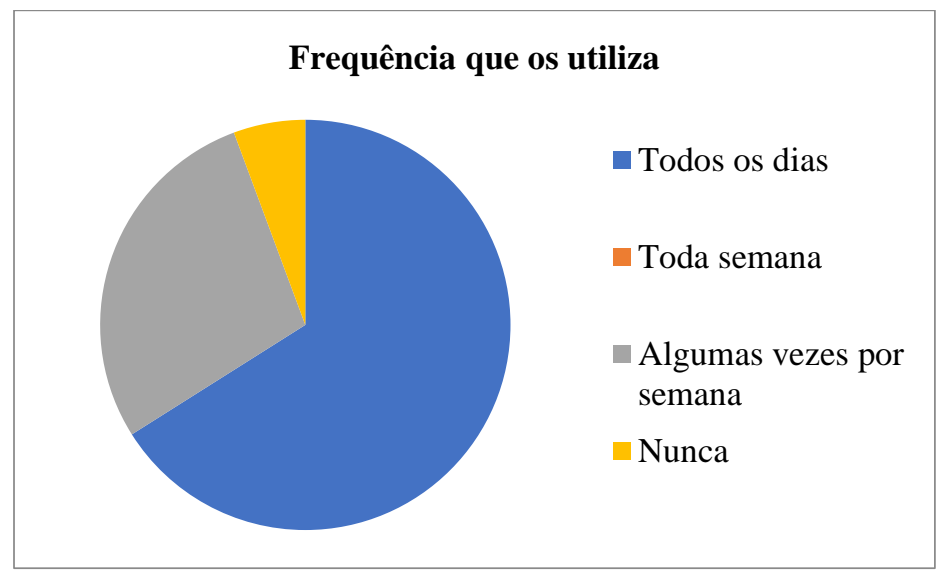

Gráfico 2: Elaborado pelos autores (2019)

Com relação a esse resultado, pode notar que mais da metade dos alunos utilizam os aparelhos digitais todos os dias. Uma parcela destes utiliza algumas vezes por semana e uma minoria nunca utiliza os referidos aparelhos.

A terceira pergunta abordou a utilização do computador para a realização das tarefas escolares:

Educação In Loco, v.01, n. 01, jan.-jun. 2020 


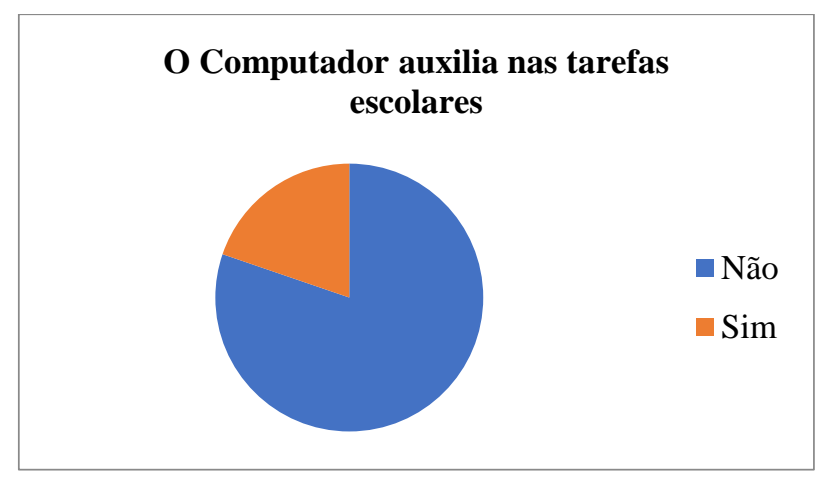

Gráfico 3: Elaborado pelos autores (2019)

No gráfico acima pode-se observar que a maioria dos alunos respondeu que o computador não auxilia em suas tarefas de casa. E uma pequena parte afirmou que utiliza o computador para a realização das tarefas de casa. Deve-se a isso o pouco uso dos recursos tecnológicos na escola e também porque em casa apenas uma parcela dos alunos possui computadores.

A quarta pergunta buscou identificar quem auxilia os alunos no uso dos equipamentos tecnológicos:

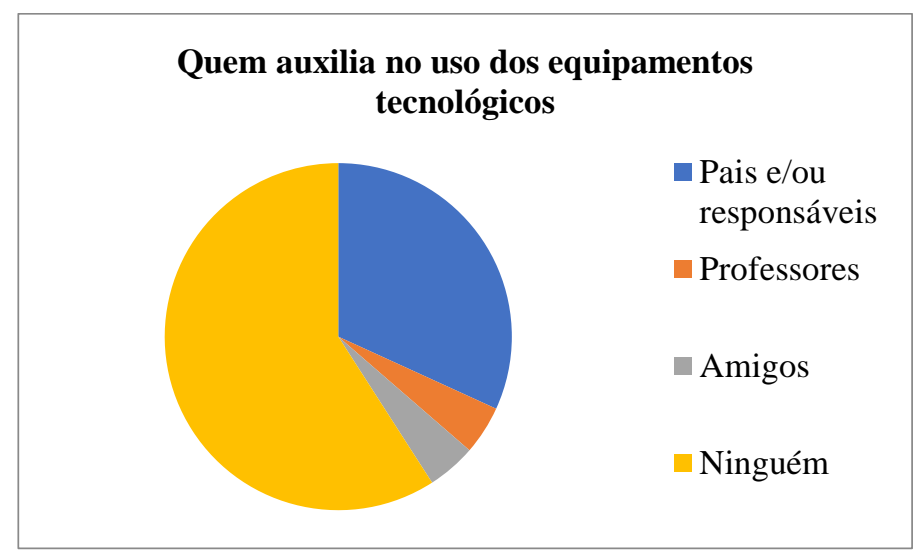

Gráfico 4: Elaborado pelos autores (2019)

A maioria dos alunos respondeu que ninguém os auxilia no uso dos equipamentos tecnológicos. Uma parcela significativa respondeu Educação In Loco, v.01, n. 01, jan.-jun. 2020 
que possuem o auxílio dos pais e/ou responsáveis e professores e amigos ajudam muito pouco. Com relação a essa pergunta, é preocupante que as crianças não tenham supervisão de um adulto, pois sabe-se que na internet pode-se ter acesso a conteúdo impróprios para menores.

A quinta pergunta buscou identificar o local que o aluno mais utiliza o computador:

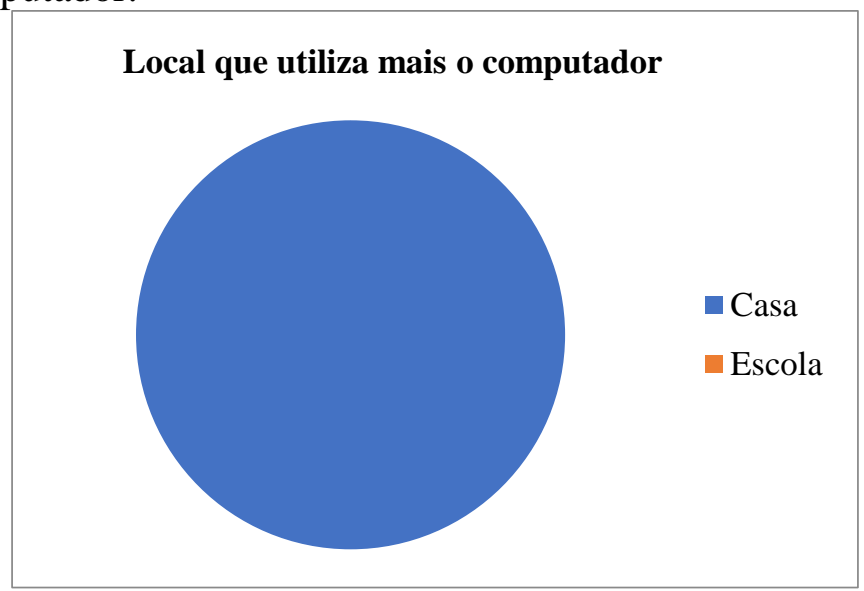

Gráfico 4: Elaborado pelos autores (2019)

As respostas foram unânimes e os alunos revelaram que utilizam o computador somente em casa. Na escola, infelizmente o uso é limitado, pois possuem 10 computadores, mas somente 3 estão funcionando. Tal fato prejudica e limita a utilização. Outra identificação é o fato de que o acesso à internet na escola também é ruim, não funciona. Dessa forma, o aluno que não tem computador em casa também não tem contato com a informática na escola.

A sexta pergunta objetivou identificar o que os alunos costumam acessar quando estão navegando na internet: 


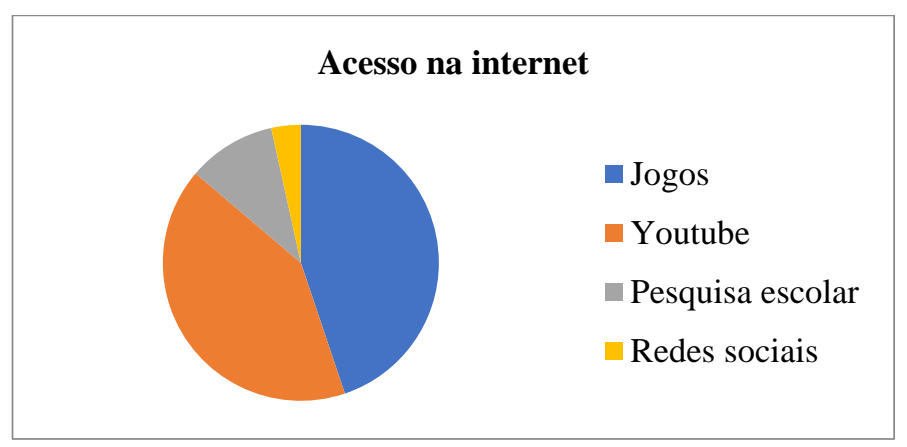

Gráfico 5: Elaborado pelos autores (2019)

Observa-se que praticamente a metade dos alunos acessa jogos on-line, enquanto uma parte considerável destes acessa o Youtube. Poucos alunos utilizam de fato a internet para realizar pesquisas escolares e uma pequena parcela acessa as redes sociais. Quanto ao uso dos jogos, é interessante que os pais e/ou responsáveis monitorem, pois existem alguns jogos que não são recomendados para crianças por terem uma natureza muito violenta, o que não é bom para quem ainda está formando sua personalidade.

Por fim, a última pergunta foi para saber com que frequência os alunos utilizam o Laboratório de Informática da escola:

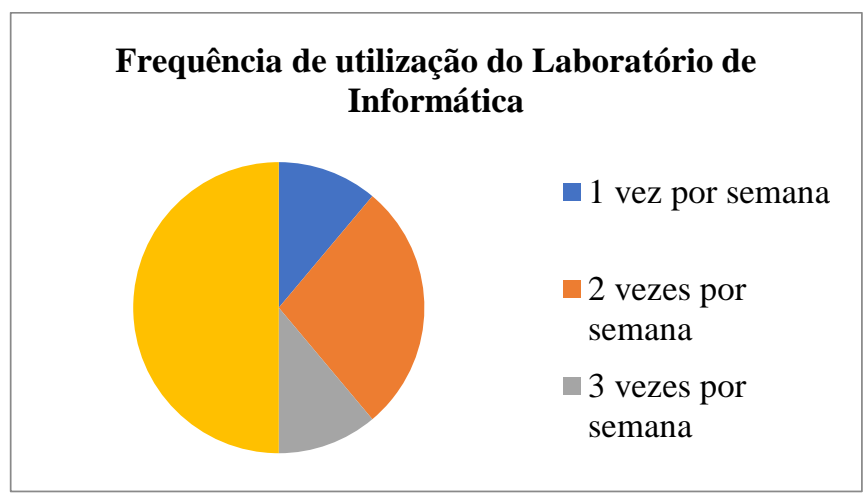

Gráfico 6: Elaborado pelos autores (2019)

A metade dos alunos que respondeu ao questionário disseram que vão ao laboratório de informática da escola uma vez por mês. Por sua vez, uma parcela considerável dos alunos respondeu que duas 
vezes por semana eles vão ao laboratório e uma parcela pequena dos alunos disse que vão uma vez por semana e três vezes por semana. Infere-se desse resultado que os alunos acreditam que vão muito pouco ao laboratório de informática da escola, e isso deve-se ao fato já mencionado da escola não oferecer as condições necessárias para que o aluno possa ter o acesso adequado aos recursos tecnológicos da escola.

A professora da turma do $3^{\circ}$ ano também respondeu a um questionário proposto pela pesquisa. Segue abaixo o questionário com as respostas da professora:

O que é inclusão digital para você, no ambiente escolar? O que está faltando para uma maior acessibilidade às ferramentas tecnológicas nas escolas?

Faz com que os alunos tenham acesso aos recursos tecnológicos para auxiliar no processo de ensinoaprendizagem. No caso da escola, computadores que funcionem, apesar de ter sala de informática, os computadores não funcionam como deveriam. Às vezes nem ligam e quando ligam não tem acesso à internet.

Qual a importância do uso dos computadores e das demais tecnologias no processo ensino-aprendizagem dos seus alunos? "Eu os utilizo para tornar as aulas mais interessantes e chamativas".

Com a instalação das máquinas, como tem sido o contato dos alunos com essa inclusão? Positivo ou Negativo? "Infelizmente o acesso dos alunos é limitado por ter apenas 3 computadores funcionando. Uso em sala de aula meu notebook e data show”.

Quais as maiores dificuldades que vocês encontram ao inserir e conteúdos com o apoio das máquinas e internet?

Falta de conhecimento sobre as máquinas?

Falta de conhecimento sobre o acesso à internet?

As duas coisas? "Não tenho dificuldade, somente falta de equipamentos que realmente funcione”.

A escola oferece apoio ou cursos profissionalizantes aos professores que não possuem facilidade ou pouca informação com os recursos digitais? 
Sim Não $(X)$

O professor ao utilizar desses recursos tecnológicos a favor do conteúdo, torna-se um mediador do conhecimento?

$\operatorname{Sim}(X)$ Não

Observando as respostas da professora, nota-se certo descontentamento desta com a falta de recursos tecnológicos que funcionem para que ela possa aliar o processo de ensino-aprendizagem à era digital do século XXI. Ela não tem dificuldades quanto ao uso e manuseio do computador, apenas falta a escola disponibilizar computadores que funcionem, principalmente o acesso à internet, pois assim facilitaria seu uso para fins pedagógicos.

$\mathrm{O}$ último questionário foi aplicado à diretora da escola. Segue abaixo o questionário com as respectivas respostas:

Dê sua opinião a respeito da importância da inclusão digital no processo de ensino e aprendizagem. "Atualmente é dificil o tema educação sem considerar as novas tecnologias de informação $e$ comunicação".

São feitas reuniões para tratar da utilização, manuseio e inserção dos equipamentos digitais na escola?

$\operatorname{Sim}(\mathrm{X}) \quad$ Não

O uso dos computadores e demais tecnologias da informação aumenta a interatividade entre alunos e professores?

$\operatorname{Sim}(X)$ Não

Como você considera a sua formação sobre o uso das tecnologias na sua carreira de gestora?

Insuficiente

Regular

Satisfatório (X)

Ótimo

Você, como gestora, orienta e auxilia os docentes ao planejar e aplicar as tecnologias em sala de aula?

Oriento a trabalhar de uma maneira integrada aliando educação com tecnologia, inserir e utilizar cada vez mais como ferramenta pedagógica às novas tecnologias de informação e comunicação, neste sentido, as escolas já estão realizando o seu papel no 
que se refere a construção do conhecimento em sala de aula.

Quais mudanças são notáveis por ter incorporado tecnologias nas aulas?

"Interesse por parte dos alunos, mas infelizmente parte do corpo docente que ainda não está preparado ou aberto para aliar a tecnologia ao trabalho no processo de ensino-aprendizagem, exigindo dos gestores educacionais um posicionamento quanto ao quê e como fazer para dispor os múltiplos recursos da informática a serviço da educação".

Observa-se que a diretora sabe da importância da inclusão digital na escola e que há limitações ainda por parte do corpo docente de aceitação dessa inclusão e de como deverá ser feita essa inclusão.

\section{Considerações Finais}

Tendo em vista a pesquisa feita e o questionário aplicado para a turma do $3^{\circ}$ ano do Ensino Fundamental da Escola Municipal Doutor Sérgio Ulhoa, na cidade de Guarda-Mór - Minas Gerais, apesar de a Escola ter adquirido computadores, estes não funcionam adequadamente e apenas três deles podem ser utilizados pelos alunos.

Nota-se que há interesse da parte da Direção em fazer a inclusão digital para que o processo ensino-aprendizagem seja completo, mas há certa resistência da parte do corpo docente quanto ao processo de inclusão e também há as dificuldades existentes no tocante ao funcionamento adequado dos equipamentos disponibilizados para os alunos.

Quanto aos alunos, há interesse nas aulas de informática na escola, mesmo porque existem alguns alunos que não possuem computadores em casa, então o único contato que eles têm é na escola com esse recurso tecnológico.

Por fim, averígua-se a necessidade de se disponibilizar recursos tecnológicos, com internet de boa qualidade que atenda satisfatoriamente a demanda e que esteja sempre disponível para que 
alunos e professores possam ter um completo aproveitamento e fazer uso dessa ferramenta pedagógica que essencial nos dias de hoje e o serão nos anos seguintes.

\section{Referências bibliográficas}

AMAGI, I. Melhorar a qualidade do ensino escolar, In: DELORS, Jacques (org). Educação: um tesouro a descobrir. $2^{a}$ ed., São Paulo: Cortez, 1999. pp. 218-220.

BONIS, S. de. Nas Malhas da Rede. In Revista Educação, São Paulo: Editora Segmento, ano 26, n⿳2 226, p. 32-41, fevereiro de 2000.

CITELLI, A. O., et al. Outras Linguagens na Escola: publicidade, cinema e TV, rádio, jogos, informática. $2^{\circ}$ ed. São Paulo: Cortez, 2001. COSTA, L. M.; FORNO, G. M. B. D. Inclusão digital nas escolas: uma realidade para todos? um estudo a partir das escolas da rede estadual de ensino no Município de Santa Maria. Santa Maria: s.n.

CYSNEIROS, P. G. Professore s Máquinas: uma concepção de informática na educação.<www.proinfor.gov.br> 2000.

FREIRE, F. M. P.; VALENTE, J. A. Aprendendo para a vida: os computadores na sala de aula. São Paulo: Cortez, 2001.

GEREMIAS, B. Medeiros. Entre o lápis e o mouse: práticas docentes e tecnologias da comunicação digital. Recife: Editora da UFP, 2011.

LOYOLA, G. F. Me adiciona.com: Ensino de Arte + Tecnologias Contemporâneas + Escola Pública. Minas Gerais: UFMG, 2009, 148 p. Dissertação (Mestrado): Programa de Pós-Graduação em Artes da Escola de Belas Artes, Universidade Federal de Minas Gerais, Minas Gerais, 2009. Disponível em: <https://repositorio.ufmg.br/bitstream/1843/JSSS-

7WSQ3H/1/me_adiciona_com_ensino_de_arte_tecnologias_contem por_neas_escola_p_blica.pdf>. Acesso em 08 out. de 2019. MERCADO, L. P. L. Novas Tecnologias na Educação: Reflexões sobre a Prática. Maceió: Edufal, 2002.

MORAES, M. C. As Novas Tecnologias da Informação e a Capacitação de Professores. Washington/DC, 1997. MORAES, M. C. O paradigma educacional emergente. Campinas: Papirus, 1997. 
OLIVEIRA, P. R. F.; FILHO, . S. M. C.; MEDEIROS, R. A. Inclusão digital: o papel da escola no contexto da cibercultura. Editora Realize, 2016.

OPUS PESQUISA E OPINIÃO. Pesquisa Quantitativa. Disponível em<http: $\quad$ https://www.opuspesquisa.com/blog/tecnicas/pesquisaquantitativa/>. Acesso em 02 de nov. 2019.

PIAGET, J. Epistemologia genética, $3^{\text {a }}$. ed,. São Paulo: Martins Fontes, 2007.

PISCHETOLA, M. Inclusão digital e Educação: A nova cultura da sala de aula. Petrópolis: Vozes, 2019.

SANCHO, J. Para um Tecnologia Educacional. Porto Alegre: Artes Médicas, 1988.

SILVEIRA, S. A. da. Inclusão digital, softwares livres e globalização contra-hegemônica. In: SILVEIRA. Sérgio Amadeu da; CASSINO, João (Org). Software livre e inclusão Digital. São Paulo: Covad, 2001. Cap1, p. 17-47.

SILVEIRA, S. A. da. Exclusão Digital: a miséria na era da informação. São Paulo: Fundação Perseu Abramo. 2005. 